\title{
Access to cannabis retail stores across Canada 6 months following legalization: a descriptive study
}

\author{
Daniel T. Myran MD MPH, Catherine R.L. Brown MD MSc, Peter Tanuseputro MD MHSc
}

\section{Abstract}

Background: On Oct. 17, 2018, Canada legalized recreational cannabis with the dual goals of reducing youth use and eliminating the illicit cannabis market. We examined factors associated with access to physical cannabis stores across Canada 6 months following legalization.

Methods: We extracted the address and operating hours of all legal cannabis stores in Canada from online government and private listings. We conducted a descriptive study examining the association between private/hybrid (mixture of government and private stores) and government-only retail models with 4 measures of physical access to cannabis: store density, weekly hours of operation, median distance to the nearest school and relative availability of cannabis stores between low- and high-income neighbourhoods.

Results: Six months after legalization, there were 260 cannabis retail stores across Canada: 181 privately run stores, 55 governmentrun stores and 24 stores in the hybrid retail system. Compared to jurisdictions with a government-run model, jurisdictions with a private/hybrid retail model had $49 \%$ (95\% confidence interval $10 \%-200 \%)$ more stores per capita, retailers were open on average 9.2 more hours per week, and stores were located closer to schools (median $166.7 \mathrm{~m}$ ). In both retail models, there was over twice the concentration of cannabis stores in neighbourhoods in the lowest income quintile compared to the highest income quintile.

Interpretation: Marked differences in physical access to cannabis retail are emerging between jurisdictions with private/hybrid retail models and those with government-only retail models. Ongoing surveillance including monitoring differences in cannabis use and harms across jurisdictions is needed.

n Oct. 17, 2018, Bill C-45, the Cannabis Act, came into effect, allowing adults across Canada to legally purchase and use recreational cannabis. ${ }^{1}$ The legislation has 2 stated goals: eliminating the illicit cannabis market and preventing youth from accessing cannabis. ${ }^{2}$ There are many potential benefits of legalization, including reducing the harms from criminalization of cannabis possession, regulating the content of the product and increased government revenue. However, use of cannabis is not benign: it is associated with negative health outcomes including mental health problems such as psychosis and addiction, ${ }^{3-9}$ cannabisrelated motor vehicle collisions ${ }^{10,11}$ and poisonings, particularly unintentional ones among children. ${ }^{12}$ Conceptually, meeting the dual goals of legalization will require balancing tight regulations on youth access to minimize potential health harms with ensuring appropriate access to legal and regulated cannabis to eliminate the illicit market. As Canada is the first high-income country to legalize the sale of recreational cannabis nationally, there is limited evidence to guide policies aimed at minimizing cannabis-related harms. One principle to mitigate potential use and harms, drawn from decades of experience of alcohol and tobacco policy, is to regulate the physical availability of cannabis retail stores. ${ }^{13,14}$ Such an approach was endorsed by numerous organizations including the Centre for Addiction and Mental Health, which recommended restricting hours of operation and placing caps on cannabis retail density. ${ }^{15}$

General principals governing the sale of cannabis are laid out in the Cannabis Act, but most regulations around physical retail fall to decisions by individual provincial and territorial jurisdictions. As such, Canada is in the midst of a cannabis experiment, both nationally and at the provincial and territorial level. Although there are many differences between each jurisdiction's decision to regulate the sale of cannabis, one potentially helpful comparison is whether the jurisdiction has adopted a privately run or a government-run cannabis retail system. This decision may have implications for the success of legalization, as it has been suggested that private retail models may be at odds with the public health goals of reducing youth cannabis use. ${ }^{16}$ To help guide policy-makers and further the

\section{Competing interests: None declared.}

This article has been peer reviewed.

Correspondence to: Daniel Myran, dmyra088@uottawa.ca

CMAJ Open 2019. DOI:10.9778/cmajo.20190012 
discourse on regulating cannabis sales in Canada, we examined measures of access to the physical cannabis retail market 6 months following legalization. This study had 3 objectives: 1) to examine the density of physical cannabis stores and average weekly hours of operation, 2) to examine the proximity of cannabis stores to schools and 3) to examine the association between neighbourhood income and access to cannabis retail stores. We compared these objectives between jurisdictions that allow privately run stores versus those that solely have government-run stores. We hypothesized that, consistent with observations from the alcohol control literature, ${ }^{13,17}$ private and hybrid (mixture of government and private stores) cannabis retail systems would have higher per capita retailers and longer hours of operation.

\section{Methods}

\section{Setting}

Canada has a population of 36 million and comprises 13 jurisdictions, including 10 provinces and 3 territories. Medical cannabis has been legal in Canada since 2001, and in 2018, the federal government passed the Cannabis Act, which legalized the use and sale of recreational cannabis. ${ }^{1}$ The Cannabis Act includes several national requirements including plain packaging on cannabis products, a minimum age of purchase of 18 years, and restrictions on the marketing and promotion of cannabis. ${ }^{1}$ The act allows each provincial and territorial jurisdiction to develop its own laws to regulate how cannabis is sold in physical stores and online. Jurisdictions have chosen a government-run model, a privately run model or a hybrid model. Although many jurisdictions have permitted municipalities to place additional regulations on how cannabis is sold, the present study focuses on variations between provincial and territorial jurisdictions.

Although all jurisdictions allowed the online retail of cannabis starting on Oct. 17, 2019, 3 jurisdictions placed limitations on the availability of physical cannabis retail. Ontario (Canada's largest province) originally intended to have a government-run model, but following a change in provincial government, in June 2018, it opted to switch to a privately run model and prohibited the physical retail of cannabis from legalization until Apr. 1, 2019. As of May 17, 2019, Ontario had limited the number of cannabis retail locations to 25 , and these were assigned through a lottery system. British Columbia (Canada's third-largest province) opted for a hybrid model but had opened only a single government-run store 6 months following legalization. Finally, Nunavut (Canada's smallest territory) has allowed only online sales. Regulations pertaining to the sale of cannabis in each Canadian jurisdiction and store locations are provided in Appendix 1 (available at www. cmajopen.ca/content/7/3/E454/suppl/DC1).

\section{Study design and data collection}

We conducted a descriptive study examining measures of access to physical cannabis retail stores 6 months following legalization of recreational cannabis in Canada. We collected and validated data on the location and hours of operation for all cannabis stores in Canada between Apr. 29 and May 17, 2019. We retrieved a list of all licensed legal cannabis stores in Canada by visiting the official government websites for each jurisdiction. We used a sequential approach to confirm the location and hours of operation for each store. First, we attempted to obtain store hours from government websites; next, we attempted to obtain store hours from official websites for individual stores; next, we used Google business listings to obtain store hours; and finally, if hours or location were not available online, we called stores individually to obtain this information. All data on location and hours of operation were independently dual extracted by C.R.L.B. and a research assistant into a standardized table. Disagreements were resolved by D.T.M. In addition, we extracted information about each jurisdiction's regulations on cannabis sales (e.g., permitted hours of operation) through official government websites.

\section{Study measures}

Our outcomes of interest related to access to a legal physical cannabis retail market, preventing youth from accessing cannabis (using proximity to elementary and secondary schools as a proxy) and equitable distribution of cannabis stores (using neighbourhood income quintile as a proxy). Measures included:

- Per capita density of cannabis retail stores, measured by the number of stores per 100000 population referent to the 2017 Canadian census population. ${ }^{18}$

- Hours of operation, measured as the mean total weekly hours of operation for stores.

- Proximity to schools, measured by the median Euclidean distance from each cannabis store to the nearest primary or secondary school (kindergarten through grade 12), where students are generally less than 18 years old.

- Concentration of cannabis stores in low-income neighbourhoods. We measured this concentration by calculating the relative rate of cannabis stores located within $1000 \mathrm{~m}$ from the geographic centre of neighbourhoods in the highest and lowest income quintile.

We reported each of these 4 measures by each jurisdiction, as well as aggregated by retail model.

\section{Sources of data}

We used the education layer from the CanMap content suite published by Desktop Mapping Technologies to map the location of all elementary and secondary schools in Canada $(n=15875)$. The CanMap content suite is updated quarterly with the use of data from provincial and territorial governments and cross-validated through additional public and private data listings (Lorenzo Haza, Desktop Mapping Technologies Spatial, Richmond Hill, Ontario: personal communication, 2019).

We chose dissemination area as the census unit most representative of neighbourhoods. Dissemination areas are the smallest geographic unit for which census data are released, and they generally contain $400-700$ people. ${ }^{19}$ We used data from the 2016 Canadian census to determine the total population 
and the population density of each dissemination area. In 2016, there were 56539 dissemination areas in Canada (excluding Nunavut).

We used Statistics Canada's Postal Code Conversion File Plus (PCCF+) to characterize dissemination areas by neighbourhood income quintile. ${ }^{20} \mathrm{We}$ used the variable QAIPPE (quintile of annual income per person equivalent), which factors in size of households and low-income cut-offs. The most recent version of $\mathrm{PCCF}+$ uses data from the 2006 Canadian census. We also calculated income quintiles using the median before-tax household income for each dissemination area using 2016 Canadian census data for a sensitivity analysis.

\section{Data analysis}

We conducted all data analysis in Stata version 15.1 (StataCorp) and ArcMap 10.5.1 (Environmental Systems Research Institute). We used ArcMap to geocode the addresses and postal codes of cannabis stores to a corresponding latitude and longitude, to calculate the Euclidean distance between each cannabis store and the nearest school, and to calculate the number of cannabis stores located within a 1000-m Euclidean buffer from the geographic centre (centroid) of each dissemination area.

We compared our study measures between private and hybrid retail systems and government-run retail systems. We compared differences between private/hybrid and government retail systems in the following ways: 1) per capita store density using a Poisson regression with total population as an offset, 2) the mean weekly hours of operation using a 2 -tailed $t$ test and 3) median distance between schools and the nearest cannabis store using Wilcoxon rank-sum tests. We used median distance as there was evidence of a nonnormal distribution. We used descriptive statistics to examine the mean and variance of the number of cannabis stores within $1000 \mathrm{~m}$ of the geographic centre of neighbourhoods. As the mean and variance showed evidence of overdispersion, we fit negative binomial regression models to estimate the association between neighbourhood income quintiles and cannabis access. We offset the regressions by the total population of each dissemination area and interpreted our exponentiated $\beta$ coefficients as rate ratios per capita. We also adjusted our final models based on the population density of each dissemination area. Given that the neighbourhood income variable uses data from the 2006 census, we conducted a sensitivity analysis using unadjusted neighbourhood income quintiles from the 2016 census. Statistical significance was set a priori at $p<0.05$.

\section{Ethics approval}

Given that all data were publicly available, no research ethics approval was required.

\section{Results}

Six months following legalization, there were 260 cannabis stores operating in Canada: 181 privately run stores in Newfoundland and Labrador, Manitoba, Saskatchewan, Alberta and Ontario, 55 government-run stores in Prince Edward Island, Nova Scotia, New Brunswick, Quebec and the Northwest Territories, and 24 stores in the hybrid retail system in British Columbia and the Yukon Territory (2 public stores and 22 private stores) (Table 1). Every jurisdiction in Canada except Nunavut had an operating physical cannabis store. Table 2 shows each jurisdiction's approach to regulating the sale of recreational cannabis, including the legal age of purchase and hours of sale.

\section{Access to cannabis retail}

Overall access to cannabis stores was higher in jurisdictions that opted for a private/hybrid retail model than in those with a government-run retail model. Regions with private/hybrid systems had 49\% (95\% confidence interval [CI] 10\%-200\%) more cannabis stores per capita than those with governmentoperated cannabis retail (0.8 v. 0.5 stores per $100000, p=$ $0.009)$. When we excluded Ontario from our analysis, this difference increased to $279 \%$ more stores per capita (1.6 v. 0.5 ) in private/hybrid retail models compared to government models. On average, retail stores in jurisdictions with private/ hybrid models were open 9.2 hours per week longer than stores in jurisdictions with government-run models (mean 76.4 h v. $67.3 \mathrm{~h}$ per week, $p<0.001$ ). Private/hybrid stores were located $166.7 \mathrm{~m}$ closer to a primary or secondary school than government stores (median distance to nearest school $577.7 \mathrm{~m}$ v. $744.4 \mathrm{~m}, p=0.04)$.

While extracting data, we identified additional stores that were in various stages of approval but were not yet open with an official licence. This included 112 stores in jurisdictions with private retail models (87 in Alberta, 23 in Ontario and 2 in Saskatchewan) and 25 stores in those with hybrid models (24 in BC and 1 in the Yukon Territory). There were no stores in jurisdictions with government-run models listed in these stages of approval.

\section{Cannabis retail by neighbourhood income}

When we compared the number of cannabis stores located within $1000 \mathrm{~m}$ from the geographic centre (centroid) of each dissemination area, both private/hybrid retail systems (incidence rate ratio $2.3,95 \%$ CI 2.0-2.8) and governmentrun systems (incidence rate ratio 3.1, 95\% CI 2.2-4.3) had more stores per capita in the lowest than the highest neighbourhood income quintile (Table 3). There was no significant difference in this relation between private and government-run systems $(p=0.2)$. The sensitivity analyses using income quintiles calculated from the 2016 Canadian census did not change the direction of the reported effect sizes (Appendix 2, available at www.cmajopen.ca/content/7/3/ E454/suppl/DC1).

\section{Interpretation}

Six months following legalization, there were 260 cannabis stores operating in Canada. Marked discrepancies in access to cannabis stores have emerged between jurisdictions. In general, regions that have selected a model that permits private 
Table 1: Cannabis retail stores per capita and key neighbourhood characteristics*

\begin{tabular}{|c|c|c|c|c|c|}
\hline $\begin{array}{l}\text { Retail model; } \\
\text { jurisdiction† }\end{array}$ & $\begin{array}{l}\text { Population } \\
(2017)^{18}\end{array}$ & $\begin{array}{l}\text { No. of licensed } \\
\text { cannabis } \\
\text { stores }\end{array}$ & $\begin{array}{l}\text { No. of stores } \\
\text { per } 100000 \\
\text { population }\end{array}$ & $\begin{array}{l}\text { No. of hours } \\
\text { of operation } \\
\text { per week, } \\
\text { mean } \pm \text { SD }\end{array}$ & $\begin{array}{c}\text { Distance to } \\
\text { nearest school, } \\
\text { m, median (IQR) }\end{array}$ \\
\hline \multicolumn{6}{|c|}{ Private/hybrid (mixture of government and private) } \\
\hline $\begin{array}{l}\text { Yukon Territory } \\
\text { (hybrid) }\end{array}$ & 38459 & $\begin{array}{c}2 \\
\text { (1 private, } \\
1 \text { government) }\end{array}$ & 5.2 & $53.5 \pm 19.1$ & $494.3(561.1)$ \\
\hline $\begin{array}{l}\text { British Columbia } \\
\text { (hybrid) }\end{array}$ & 4290988 & $\begin{array}{c}22 \\
\text { (21 private, } \\
1 \text { government) }\end{array}$ & 0.5 & $71.0 \pm 17.4$ & $405.9(406.2)$ \\
\hline Alberta & 4286134 & 86 & 2.0 & $77.2 \pm 13.0$ & $549.6(454.3)$ \\
\hline Saskatchewan & 1163925 & 29 & 2.5 & $70.8 \pm 11.4$ & $637.6(325.2)$ \\
\hline Manitoba & 1338109 & 23 & 1.7 & $79.0 \pm 6.9$ & $540.0(318.5)$ \\
\hline Ontario & 14193384 & 18 & 0.1 & $83.5 \pm 10.4$ & $452.2(262.3)$ \\
\hline $\begin{array}{l}\text { Newfoundland and } \\
\text { Labrador }\end{array}$ & 528817 & 25 & 4.7 & $79.7 \pm 12.5$ & $871.1(917.9)$ \\
\hline Total & 25839816 & 205 & $0.8 \ddagger$ & $76.4 \pm 13.2 \S$ & 577.7 (468.5)ף \\
\hline \multicolumn{6}{|l|}{ Government } \\
\hline Northwest Territories & 44520 & 5 & 11.2 & $41.8 \pm 17.6$ & $652.7(164.8)$ \\
\hline Quebec & 8394034 & 14 & 0.2 & $59.1 \pm 4.2$ & $525.1(940.9)$ \\
\hline New Brunswick & 759655 & 20 & 2.6 & $71.0 \pm 0$ & $549.6(454.3)$ \\
\hline Nova Scotia & 953869 & 12 & 1.3 & $77.0 \pm 0$ & $831.8(408.2)$ \\
\hline Prince Edward Island & 152021 & 4 & 2.6 & $79.5 \pm 7.0$ & $530.5(334.7)$ \\
\hline Total & 10304099 & 55 & $0.5 \ddagger$ & $67.3 \pm 12.0 \S$ & 744.4 (619.6)ף \\
\hline Grand total & 36143915 & 260 & 0.7 & $74.5 \pm 13.4$ & $598.13(489.9)$ \\
\hline \multicolumn{6}{|c|}{$\begin{array}{l}\text { Note: IQR = interquartile range, } \mathrm{SD}=\text { standard deviation. } \\
\text { *Sources are provided in Appendix } 1 . \\
\text { †Nunavut has no physical cannabis stores and was excluded from all analyses. } \\
\ddagger p=0.009 \text { for difference between jurisdictions with private and public models offset by total population (Poisson regression). } \\
\$ p<0.0001 \text { for difference between private/hybrid and government models ( } t \text { test). } \\
\uparrow p=0.047 \text { for difference between private/hybrid and government models (rank sum test). }\end{array}$} \\
\hline
\end{tabular}

cannabis retailers had greater access to physical cannabis sales, with more stores per capita that are also open longer. In addition, stores in private/hybrid models were located closer to schools than those in government-run models. Data from the first 6 months following legalization suggest that the number of stores will expand more rapidly in private retail systems than in government retail systems except where governments have limited the number of retail outlets (Ontario). Finally, access to physical cannabis retailers in both private/hybrid and government-only models is concentrating more in lowincome neighbourhoods.

We observed increased physical and temporal access to cannabis retail in private and hybrid cannabis retail systems compared to government systems. These findings are consistent with evidence from the alcohol control literature that suggests that private retail systems generally have higher access to alcohol sales and lead to higher levels of alcohol consumption. $^{21,22}$ The implications of our findings depend on policy priorities and on the currently unknown relation between access to cannabis retail and cannabis use and associated harms. Policy-makers primarily concerned with eliminating the illicit cannabis market could perceive increased physical access in private and hybrid retail systems as a marker of success for these systems. Conversely, policy-makers focused on curbing youth and problematic cannabis use may be concerned that cannabis will follow similar patterns observed in the alcohol and tobacco control literature, where increased access to alcohol and tobacco retail is associated with higher use and subsequent harms. ${ }^{23-27}$ Although cannabis has important differences from alcohol and tobacco, and caution should be used when applying this literature to cannabis, all 3 are mood-altering substances that can result in addiction. ${ }^{9}$ Should trends with cannabis retail similar to those with alcohol retail occur, populations living in private and hybrid retail systems may exhibit higher cannabis use than those living in government systems.

Our finding of concentration of cannabis retail access in low-income neighbourhoods is consistent with research from the United States. A California study showed that legal medical cannabis dispensaries concentrate in low-income 
Table 2 (part 1 of 2): Description of how each Canadian province and territory is allowing cannabis retail and online sales*

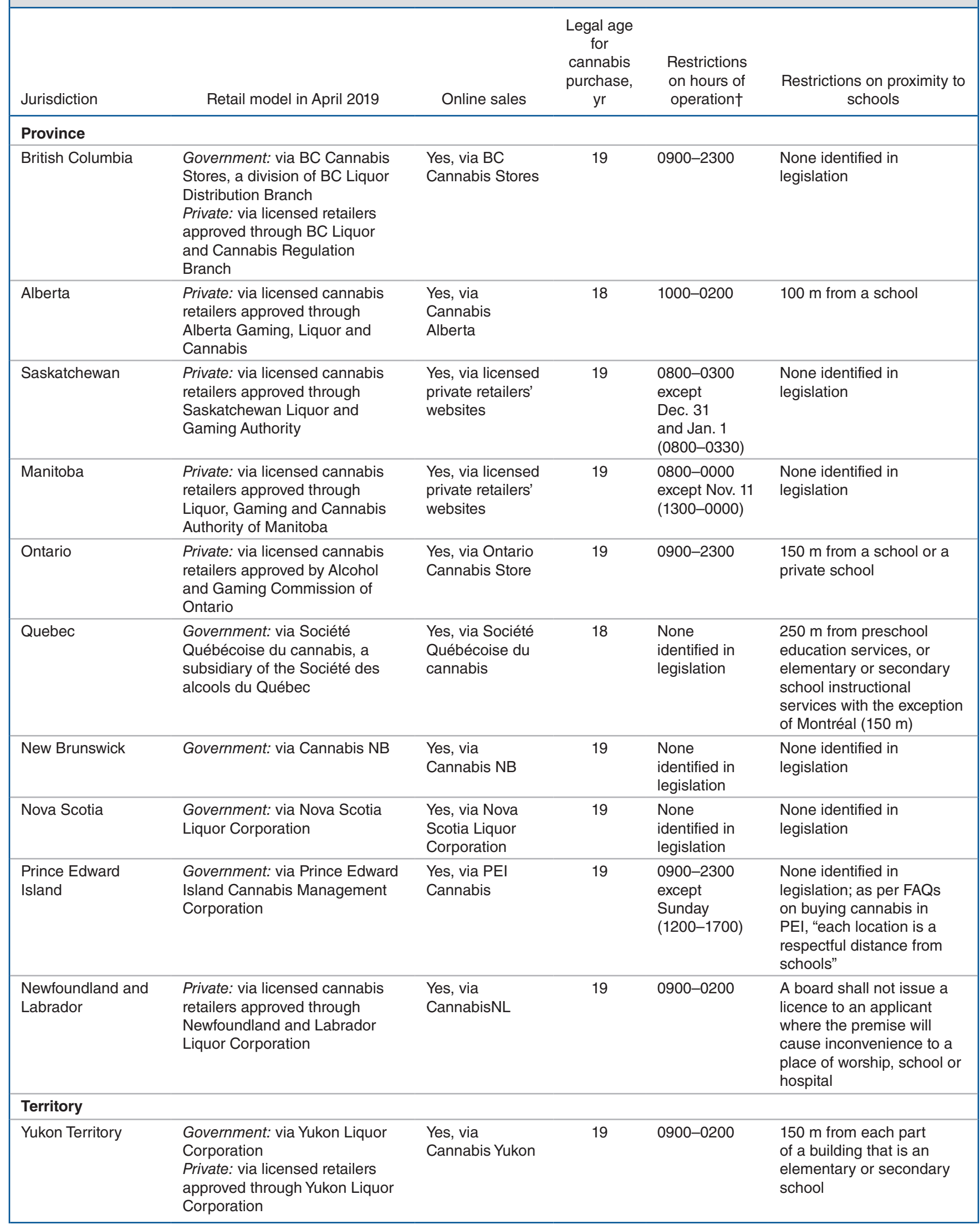


Table 2 (part 2 of 2): Description of how each Canadian province and territory is allowing cannabis retail and online sales*

\begin{tabular}{|c|c|c|c|c|c|}
\hline Jurisdiction & Retail model in April 2019 & Online sales & $\begin{array}{l}\text { Legal age } \\
\text { for } \\
\text { cannabis } \\
\text { purchase, } \\
\text { yr }\end{array}$ & $\begin{array}{l}\text { Restrictions } \\
\text { on hours of } \\
\text { operation† }\end{array}$ & $\begin{array}{c}\text { Restrictions on proximity to } \\
\text { schools }\end{array}$ \\
\hline $\begin{array}{l}\text { Northwest } \\
\text { Territories }\end{array}$ & $\begin{array}{l}\text { Government: via Northwest } \\
\text { Territories Liquor and Cannabis } \\
\text { Commission }\end{array}$ & $\begin{array}{l}\text { Yes, via } \\
\text { Northwest } \\
\text { Territories Liquor } \\
\text { and Cannabis } \\
\text { Commission }\end{array}$ & 19 & $\begin{array}{l}\text { None } \\
\text { identified in } \\
\text { legislation }\end{array}$ & $\begin{array}{l}\text { None identified in } \\
\text { legislation }\end{array}$ \\
\hline Nunavut & $\begin{array}{l}\text { No retail stores open as of } \\
\text { May } 17,2019\end{array}$ & $\begin{array}{l}\text { Yes, via } \\
\text { approved agents } \\
\text { for online sales } \\
\text { from Nunavut } \\
\text { Liquor and } \\
\text { Cannabis }\end{array}$ & 19 & $\begin{array}{l}\text { Maximum of } \\
12 \mathrm{~h} \text { during } \\
\text { any } 24-\mathrm{h} \\
\text { period }\end{array}$ & $\begin{array}{l}\text { None identified in } \\
\text { legislation }\end{array}$ \\
\hline
\end{tabular}

regions, with each US\$10 000 decrease in median household income associated with a $14.5 \%$ greater odds of the presence of a dispensary. ${ }^{28}$ As well, a study in Colorado showed that lower-income neighbourhoods had higher numbers of cannabis stores. ${ }^{29}$ Similarly, research from Canada indicated that alcohol and tobacco retail concentrates in neighbourhoods with low socioeconomic status. ${ }^{17,30,31}$ There are several possible explanations for the concentration of cannabis retailers in low-income regions, including lower levels of rent or property tax, higher expected market demand for cannabis and commercial zoning bylaws that may exclude stores from higher-income neighbourhoods. The concentration of cannabis stores in low-income neighbourhoods and near schools raises concerns that use and harms may concentrate in vulnerable populations. Jurisdictions may wish to take the time to find the desired balance between ensuring access to legally produced and regulated cannabis while limiting access to youth and other vulnerable populations. Experience from the tobacco and alcohol industries, however, has shown that increasing regulations on established industries has many challenges. ${ }^{16,32,33}$ There is a clear need for high-quality studies that generate evidenceinformed recommendations to regulate the cannabis retail environment and find the correct balance between the dual goals of legalization. In the interim, policy-makers and the public will need to make pragmatic judgments about the preferred level of cannabis retail availability.

\section{Limitations}

There are several limitations to this study. First, our analysis compares public and private retail models but fails to take into account other differences between the jurisdictions, such as number of major cities and demographic differences in age and sex. Second, cannabis retail will undoubtedly continue to develop, so these preliminary findings may not accurately represent a more mature market. Third, our search of online listings may have underestimated the number of stores if governments were delayed in updating these listings. Fourth, we used Euclidean distance, a simple measure of distance, for our spatial analysis. Although this measure is easy to calculate and communicate, it may underestimate true distances (i.e., it could ignore road features that create much larger travel distances). Future work should use more sophisticated measures of access including travel time along road networks and spatial access measures. ${ }^{22,34}$ Fifth, we were unable to account for the size of stores. Living near a large retail storefront may provide greater access than living near a smaller store, which may have biased our results. Finally, we limited this study to legal physical cannabis retail, yet all Canadian provincial and territorial governments are allowing online sales. In addition, at the time of our analysis, Statistics Canada estimated that a large illicit cannabis market was still present in Canada. ${ }^{35}$ Nonetheless, experts predict that the majority of cannabis retail will be through bricks-and-mortar stores and that the illicit market will soon be replaced by the legal market. ${ }^{36}$ Consequently, legal cannabis retail stores likely represent a future critical point of access to the market.

\section{Conclusion}

Six months following legalization, there was greater access to cannabis, including closer proximity to schools, in jurisdictions with private/hybrid cannabis retail systems than in those with government-only systems. In addition, cannabis stores across Canada are concentrating in low-income neighbourhoods. Ongoing research is required to determine whether these patterns of access to cannabis retail are related to health-associated harms from cannabis use. In the interim, policy-makers and communities should carefully consider whether these emerging trends reflect the desired balance 
Table 3: Negative binomial regression comparing cannabis stores per capita within $1000 \mathrm{~m}$ of the geographic centre of neighbourhoods in the lowest income quintile (Q1) and the highest income quintile (Q5)

\begin{tabular}{|c|c|c|}
\hline \multirow{2}{*}{$\begin{array}{l}\text { Retail model; } \\
\text { jurisdiction }\end{array}$} & \multicolumn{2}{|c|}{$\begin{array}{c}\text { Incident rate ratio }(95 \% \mathrm{Cl}), \mathrm{Q1}: \mathrm{Q} 5 \\
\text { (reference) }\end{array}$} \\
\hline & Model $A^{*}$ & Model B* \\
\hline \multicolumn{3}{|l|}{ Private/hybrid } \\
\hline $\begin{array}{l}\text { Yukon Territory } \\
\text { (hybrid) }\end{array}$ & $-\dagger$ & $-\dagger$ \\
\hline $\begin{array}{l}\text { British Columbia } \\
\text { (hybrid) }\end{array}$ & $2.73(1.83-4.06)$ & 2.02 (1.34-3.05) \\
\hline Alberta & $2.89(2.16-3.88)$ & 2.42 (1.79-3.27) \\
\hline Saskatchewan & 2.27 (1.26-4.07) & $1.75(0.97-3.17)$ \\
\hline Manitoba & 4.89 (2.71-8.84) & $3.04(1.66-5.58)$ \\
\hline Ontario & $1.44(1.02-2.05)$ & $1.02(0.71-1.48)$ \\
\hline $\begin{array}{l}\text { Newfoundland and } \\
\text { Labrador }\end{array}$ & $2.47(1.36-4.51)$ & $1.32(0.74-2.34)$ \\
\hline Total & $2.64(2.22-3.14)$ & $2.33(1.96-2.79) \ddagger$ \\
\hline \multicolumn{3}{|l|}{ Government } \\
\hline $\begin{array}{l}\text { Northwest } \\
\text { Territories }\end{array}$ & $0.63(0.10-3.75)$ & $0.66(0.11-3.97)$ \\
\hline Quebec & $4.24(2.57-7.00)$ & $2.84(1.65-4.91)$ \\
\hline New Brunswick & $2.41(1.22-4.78)$ & $1.72(0.84-3.52)$ \\
\hline Nova Scotia & $4.63(2.14-10.04)$ & $3.74(1.73-8.16)$ \\
\hline $\begin{array}{l}\text { Prince Edward } \\
\text { Island }\end{array}$ & $3.89(0.82-18.33)$ & $1.66(0.27-9.99$ \\
\hline Total & $3.50(2.50-4.91)$ & $3.05(2.16-4.31) \ddagger$ \\
\hline Grand total & $2.71(2.32-3.16)$ & 2.33 (1.98-2.72) \\
\hline \multicolumn{3}{|c|}{$\begin{array}{l}\text { Note: } \mathrm{Cl}=\text { confidence interval. } \\
\text { *Both models are offset by the total population of a dissemination area. Model B } \\
\text { adjusts for the population density of each dissemination area in people per } \\
\text { square kilometre. } \\
\text { tUnstable regression model, as income has near-perfect prediction for the } \\
\text { dependent variable. } \\
\text { fInteraction between private/hybrid retail system v. government retail system and } \\
\text { income quintiles was not significant }(p=0.2) \text {. }\end{array}$} \\
\hline
\end{tabular}

between the dual goals of cannabis legalization: eliminating the illicit cannabis market and preventing youth from accessing cannabis.

\section{References}

1. An Act respecting cannabis and to amend the Controlled Drugs and Substances Act, the Criminal Code and other Acts. 42nd Parliament, 1st sess, 2018 June 21. Available: www.parl.ca/DocumentViewer/en/42-1/bill/C-45/royal -assent (accessed 2018 Aug. 1).

2. What you need to know about cannabis: cannabis in Canada - get the facts. Ottawa: Health Canada; modified 2019 Mar. 11. Available: www.canada.ca/en/ services/health/campaigns/cannabis/canadians.html (accessed 2018 Dec. 1).

3. Large M, Sharma S, Compton MT, et al. Cannabis use and earlier onset of psychosis: a systematic meta-analysis. Arch Gen Psychiatry 2011;68:555-61.

4. Crippa JA, Zuardi AW, Martín-Santos R, et al. Cannabis and anxiety: a critical review of the evidence. Hum Psychopharmacol 2009;24:515-23.

5. Imtiaz S, Shield KD, Roerecke M, et al. The burden of disease attributable to cannabis use in Canada in 2012. Addiction 2016;111:653-62.

6. Chen CY, Storr CL, Anthony JC. Early-onset drug use and risk for drug dependence problems. Addict Behav 2009;34:319-22.
7. Di Forti M, Morgan C, Dazzan P, et al. High-potency cannabis and the risk of psychosis. Br 7 Psychiatry 2009;195:488-91.

8. Patton GC, Coffey C, Carlin JB, et al. Cannabis use and mental health in young people: cohort study. BM7 2002;325:1195-8.

9. Volkow ND, Baler RD, Compton WM, et al. Adverse health effects of marijuana use. NEngl f Med 2014;370:2219-27.

10. Asbridge M, Hayden JA, Cartwright JL. Acute cannabis consumption and motor vehicle collision risk: systematic review of observational studies and meta-analysis. BM7 2012;344:e536.

11. Evidence brief: driving under the influence of cannabis and risk of motor vebicle collision. Toronto: Public Health Ontario; 2017.

12. Wang GS, Le Lait MC, Deakyne SJ, et al. Unintentional pediatric exposures to marijuana in Colorado, 2009-2015. FAMA Pediatr 2016;170:e160971.

13. Giesbrecht N, Stockwell T, Kendall P, et al. Alcohol in Canada: reducing the toll through focused interventions and public health policies. CMA7 2011;183:450-5.

14. Levy DT, Tam J, Kuo C, et al. The impact of implementing tobacco control policies: the 2017 Tobacco Control Policy Scorecard. 7 Public Health Manag Pract 2018;24:448-57.

15. Cannabis policy framework. Toronto: Centre for Addiction and Mental Health; 2014.

16. Caulkins JP, Kilborn ML. Cannabis legalization, regulation, \& control: a review of key challenges for local, state, and provincial officials. Am 7 Drug Alcobol Abuse 2019 May 28 [Epub ahead of print]. doi: 10.1080/00952990. 2019.1611840 .

17. Myran DT, Chen J, Giesbrecht N, et al. The association between socioeconomic status and alcohol availability in Ontario following alcohol sales deregulation, 2013-2017. Am 7 Public Health 2019;109:899-905.

18. Table 17-10-0005-01: Population estimates on 7uly 1st, by age and sex. Ottawa: Statistics Canada; modified 2019 June 13. Available: https://www150.statcan.gc.ca/ t1/tbl1/en/tv.action?pid=1710000501 (accessed 2018 Nov. 30).

19. Census dictionary: dissemination area (DA). Ottawa: Statistics Canada; modified 2015 Nov. 27. Available: www12.statcan.gc.ca/census-recensement/2011/ref/ dict/geo021-eng.cfm (accessed 2018 Sept. 30).

20. Postal Code ${ }^{\mathrm{OM}}$ Conversion File Plus $(\mathrm{PCCF}+)$ version 6A, reference guide: June 2013 postal codes ${ }^{\mathrm{OM}}$. Cat no 82F0086X2014001. Ottawa: Statistics Canada; 2014.

21. Giesbrecht N, Wettlaufer A. Reducing alcohol-related harms and costs in Ontario: a provincial summary report. Toronto: Centre for Addiction and Mental Health; 2013. Available: https://www.camh.ca/-/media/files/pdfs---reports-and-books ---research/provincial-summary_on_final-pdf.pdf?la=en\&hash=D8995E153422277 F1AC062D62BCB264561749372 (accessed 2018 Feb. 7).

22. Guide for measuring alcohol outlet density. Atlanta: Centers for Disease Control and Prevention, US Department of Health and Human Services; 2017. Available: www.cdc.gov/alcohol/pdfs/CDC-Guide-for-Measuring-Alcohol-Outlet-Density .pdf (accessed 2018 Dec. 2).

23. Popova S, Giesbrecht N, Bekmuradov D, et al. Hours and days of sale and density of alcohol outlets: impacts on alcohol consumption and damage: a systematic review. Alcohol Alcohol 2009;44:500-16.

24. Henriksen L, Feighery EC, Schleicher NC, et al. Is adolescent smoking related to the density and proximity of tobacco outlets and retail cigarette advertising near schools? Prev Med 2008;47:210-4.

25. Campbell CA, Hahn RA, Elder R, et al.; Task Force on Community Preventive Services. The effectiveness of limiting alcohol outlet density as a means of reducing excessive alcohol consumption and alcohol-related harms. Am 7 Prev Med 2009;37:556-69.

26. Cantrell J, Anesetti-Rothermel A, Pearson JL, et al. The impact of the tobacco retail outlet environment on adult cessation and differences by neighborhood poverty. Addiction 2015;110:152-61.

27. Myran DT, Chen JT, Giesbrecht N, et al. The association between alcohol access and alcohol-attributable emergency department visits in Ontario, Canada. Addiction 2019;114:1183-91

28. Morrison C, Gruenewald PJ, Freisthler B, et al. The economic geography of medical cannabis dispensaries in California. Int 7 Drug Policy 2014;25:508-15.

29. Shi Y, Meseck K, Jankowska MM. Availability of medical and recreational marijuana stores and neighborhood characteristics in Colorado. 7 Addict 2016; 2016:7193740.

30. Chaiton MO, Mecredy GC, Cohen JE, et al. Tobacco retail outlets and vulnerable populations in Ontario, Canada. Int 7 Environ Res Public Health 2013; 10:7299-309.

31. Ngamini Ngui A, Apparicio P, Philibert M, et al. Neighborhood characteristics associated with the availability of alcohol outlets in Quebec, Canada. 7 Addict 2015;2015:876582.

32. Saloojee Y, Dagli E. Tobacco industry tactics for resisting public policy on health. Bull World Health Organ 2000;78:902-10.

33. Miller D, Harkins C. Corporate strategy, corporate capture: food and alcohol industry lobbying and public health. Crit Soc Policy 2010;30:564-89.

34. Holmes J, Guo Y, Maheswaran R, et al. The impact of spatial and temporal availability of alcohol on its consumption and related harms: a critical review in the context of UK licensing policies. Drug Alcohol Rev 2014;33:515-25.

35. Gross domestic product, income and expenditure, fourth quarter 2018 [news release]. Ottawa: Statistics Canada; 2019 Mar. 1.

36. A society in transition, an industry ready to bloom: 2018 cannabis report. Deloitte; 2018 
Affiliations: Clinical Epidemiology Program (Myran, Brown, Tanuseputro), Ottawa Hospital Research Institute; School of Epidemiology and Public Health (Myran, Brown), University of Ottawa; Bruyère Research Institute (Tanuseputro); Department of Medicine (Tanuseputro), University of Ottawa, Ottawa, Ont.

Contributors: Daniel Myran and Catherine Brown acquired the data, and Daniel Myran performed the data analysis. Catherine Brown and Daniel Myran drafted the article, and Peter Tanuseputro revised it critically for important intellectual content. All of the authors conceived and designed the study, interpreted the data, approved the final version to be published and agreed to be accountable for all aspects of the work.
Funding: This study received funding for open-access publication from the Bruyère Centre for Individualized Health.

Acknowledgements: The authors thank Mary Scott and Emiliyan Staykov for their help in extracting data on cannabis locations and hours of operation.

Disclaimer: The funders had no influence on the study design, analysis or interpretation, or the reporting of the study.

Supplemental information: For reviewer comments and the original submission of this manuscript, please see www.cmajopen.ca/content/7/3/ E454/suppl/DC1. 